\title{
Inhibition of the righting reflex in the common bullfrog ( Rana catesbiana) employing an operant-avoidance procedure
}

\author{
C. BRIAN HARVEY, CECIL ELLIS, and MONICA TATE \\ University of Missouri-Rolla, Department of Social Sciences, Rolla, Missouri 65401
}

\begin{abstract}
Three common bullfrogs of the Rana catesbiana strain were conditioned, employing an operant-avoidance procedure, to inhibit the high-priority, biologically adaptive righting reflex. To avoid an electric shock of $.6, .8$, or $1.0 \mathrm{~mA}$, bullfrogs, when flipped, remained passively on their backs rather than exhibiting the normal short-latency righting response. The data are discussed in the context of the species-specific aspects of avoidance behavior.
\end{abstract}

Considerable data on geotropic behavior in the common bullfrog (Rana catesbiana) suggest that position and attitude adjustments are both precise and adaptive in that they facilitate the bullfrog's survival in its natural habitat. Such behaviors were first described systematically by Dickerson (1906), who asserted that a frog is "not at ease" unless its head is uppermost. That a bullfrog can right itself with its forebrain not intact is evidence that the "righting-reflex" is, indeed, a reflex.

Researching with leopard frogs, McGill (1960) has shown that these frogs find it adaptive in escape or avoidance paradigms not to make the shuttle response but, rather, to spread out their bodies, remain passive, and take the shock. Although spreading seemed to reduce the discomfort of shock, it was maladaptive in that it led to the death of the frogs. Boice (1968) demonstrated that escape and avoidance responses are incompatible with behavioral passivity. In both researches, the shock level was extreme.

The present research attempts to answer two important questions: (a) can a high-priority biologically adaptive response, specifically the righting reflex in the common bullfrog, be brought under stimulus control and inhibited; and (b) can the bullfrog learn an operant-avoidance response?

\section{METHOD}

\section{Subjects}

The subjects were four adult male frogs of the Rana catesbiana (common bullfrog) variety captured in the wild. The frogs were housed in a metal tub which was half filled with water; laboratory temperature was maintained at $20^{\circ} \mathrm{C}$. The frogs were fed live grasshoppers and crickets for the first 3 weeks; and as live food became unavailable, they were force-fed meal worms for thenext weeks of experimentation.

Requests for reprints should be sent to C. Brian Harvey, Department of Psychology, University of Missouri-Rolla, Rolla, Missouri 65401. Dr. C. T. Morgan sponsors this paper and takes full editorial responsibility for its content.

\section{Apparatus}

Shock was delivered by a Grason-Stadler No. 700 shock generator and a Hewlett-Packard supply set at $28 \mathrm{~V}$. Probes were attached to the frogs via a wire harness wrapped around the pelvic girdle below the erostyle.

\section{Procedure}

Following 10 days of adaptation to the laboratory environment, the experiment, which consisted of 10 trials/day for 10 days, was begun. The frogs were towel dried and handled by the experimenter for $2 \mathrm{~min}$ before each session. The experimenter then loosely wrapped a wire harness, to which the probes were attached, around the pelvic girdle below the erostyle. All trials were conducted on top of a laboratory table. The experimenter placed his middle finger under the frog's jaw, tilted the frog to approximately $75 \mathrm{deg}$ for $2 \mathrm{sec}$, and flipped the frog onto its back. Immediate return to a head-uppermost position was defined as righting; inhibition was defined as the frog remaining passively on its back for $10 \mathrm{sec}$. On the first 10 trials (Day 1), the wire was wrapped around the frog's pelvic girdle; but no electric shock was administered following righting. On the remaining 90 trials (Days 2-10), the righting reflex was immediately followed by a .6-mA (Frog 1), .8-mA (Frog 2), or 1.0-mA (Frog 3) electric shock. Frog 4 died during the first 10 trials. Shock duration was randomized for 1,2 , or $3 \mathrm{sec}$. On Day 25, Frog 2 was given 20 retention trials; and on Day 30, Frog 2 was decerebrated and was given 10 trials with the wire off and 10 trials with the wire in place.

\section{RESULTS}

The data are expressed as a percentage: (total number of righting responses/total number of previous trials) $\times 100$. The difference between a datum point and $100 \%$, thus, reflects the development of learning to inhibit the righting response and to avoid electric shock. The data (see Figure 1) indicates that frogs can learn to inhibit the righting response to avoid shock. In terms of the raw data for each of the trials on Days 2-10, successful avoidance of shock by inhibition of righting occurred on 56 of 90 trials for Frog 1,85 of 90 trials for Frog 2, and 79 of 90 trials for Frog 3. Optimal shock intensity appears to be $.8 \mathrm{~mA}$. On the retention task on Day 25, Frog 2 righted on 10 of 10 trials with the wire off and inhibited righting on 10 of 10 trials with the wire on. 
Following decerebration on Day 30, Frog 2 exhibited perfect performance on 20 trials.

\section{DISCUSSION}

The results of the present experiment indicate that common bullfrogs. can learn to inhibit the highly adaptive righting reflex by employing an operant-avoidance procedure. As shown by the data of the first 10 trials, placing of the wire around the pelvic girdle did not inhibit righting. Following Trial 11, on which righting was followed by an electric shock, the frogs exhibited consistent and rather typical passive avoidance behavior.

Several manipulations made during the experiment yielded interesting results. Retention of the avoidance response was shown on Day 25, 15 days after the final series of avoidance trials. Retention of the inhibition of righting in a decerebrated frog was illustrated; it is suggested that learning to inhibit the righting reflex occurs somewhere other than in the cortical area. During Trial 30 on Day 3, Frog 1 fortuitously made a croaking noise while remaining passively on its back. For several days thereafter, it was noted that Frog 1 would croak just prior to being returned to its head-uppermost position after croaking and because croaking increased over trials, it is suggested that the frog had acquired croaking as a superstitious behavior which was noncontingently reinforced by returning the frog to its natural upright position.

Although the study can be readily understood in terms of the frogs' acquiring a simple passive avoidance response (which is interesting in and of itself), it is possible to consider the implications of the research in the light of the biological constraints on learning. Animals appear to be equipped with response systems which are basically unlearned, innate, and automatic-response systems which allow them to cope with an environment in constant flux. When presented with a novel stimulus, rats freeze, birds take flight, dogs adopt threatening postures, and frogs freeze and then hop away. Defensive reactions appear spontaneously and mechanically, for nature offers little opportunity for its membership to rehearse specific defense skills. Bolles (1970) describes such escape or avoidance behaviors as "species-specific defense reactions" (SSDRs); operantavoidance responses will be learned only if they constitute SSDRs already elicited by the stimulus situation. For example, it is notoriously difficult to train pigeons to keypeck or rats to leverpress to escape or to avoid electric shock, as pecking and leverpressing in aversive situations are rather low-probability responses in the behavioral hierarchy of the pigeon and the rat.

How can bullfrogs, thus, learn relatively unnatural responses (remaining passively on their backs) to avoid a noxious event like electric shock? Bolles (1970) suggests that animals learn that certain signals are accurate predictors of events in the environment. Cues regularly followed by noxious stimuli, such as shock, become "danger signals" while cues regularly predicting freedom or an end to aversive stimuli become "safety signals"; thus, it is not fear or fear reduction that lead to successful avoidance. Rather, Bolles (1970) indicates that danger signals evoke SSDRs which get the animal away from danger. If standard SSDRs fail to work, animals are forced to try other responses "close to" those in their natural SSDR repertoire.

The common bullfrog appears to have characteristic innate defensive behaviors that keep it out of trouble. The bullfrog's SSDR repertoire consists, at least, of freezing or hopping away. The efficiency of both receiving and responding to potentially dangerous stimuli would be highest with the bullfrog in a headuppermost position. The adaptability of righting seems to be intuitively obvious. But, apparently, there are hierarchies of species-specific behaviors such that, in some situations where multiple response choices are available, one species-specific behavior will take precedence over another lower priority response. Bullfrogs, when flipped on their backs, usually right

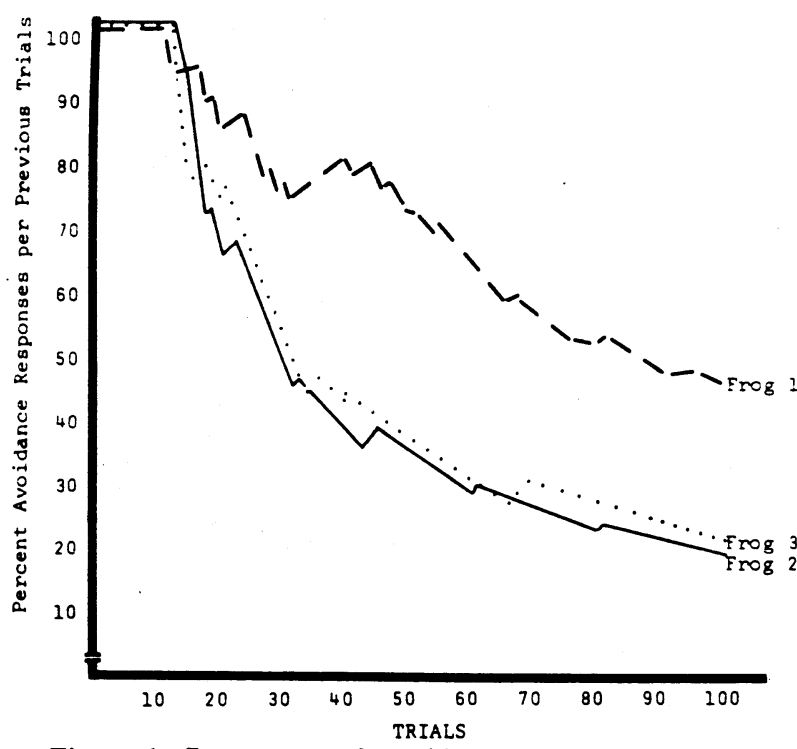

Figure 1. Percentage of avoidance responses (inhibition of the righting reflex) per previous trials.

themselves, but, if righting occasions a noxious shock, bullfrogs freeze and remain passively on their backs. The SSDR of freezing, possibly to the danger cue of the wire on, appears to take precedence over the righting reflex. With little difficulty did the bullfrogs learn to inhibit righting to avoid the shock. Even though avoidance behavior involved the inhibition of the highly adaptive righting response, the avoidance behavior required to the bullfrogs was, as Bolles (1972) has suggested, the best way to solve the problem. Learning a positive contingency in the myriad of negative contingencies involved the acquisition of a specific response (inhibition of righting) to a particular cue (the wire on) which predicts safety (as it precludes electric shock). The ease of acquisition suggests that inhibition of righting is apparently an SSDR or, at least, highly compatible with the bullfrog's SSDR arsenal.

In summary, bullfrogs can be trained to inhibit the righting reflex to avoid electric shock. It is suggested that the bullfrog has a hierarchy of genetically based behaviors, that the freezing response takes precedence over the righting reflex, and that passive-avoidance learning, in this instance, involved the acquisition of a contingency between an SSDR and a danger signal.

\section{REFERENCE NOTE}

1. Boice, Robert. Avoidance learning in active and passive frogs and toads. Presented at the Meeting of the Psychonomic Society. St. Louis. 1988.

\section{REFERENCES}

Bolles, R. C. Species specific defense reactions and avoidance learning. Psychological Review. 1970. 37. 32-48.

Bolles, R. C. The avoidance learning problem. In G. H. Bower (Ed.). The psychology of learning and motivation (Vol. 6). New York: Academic. 1972.

Dickerson. MARY C. The frog book: North American toads and frogs. New York: Dover. 1906.

McGill. Thomas. E. Response of the leopard frog to electric shock in an escape learning situation. Journal of Comparative and Physiological psychology. 1960. 53. 443-445.

(Received for publication September 26. 1975.) 